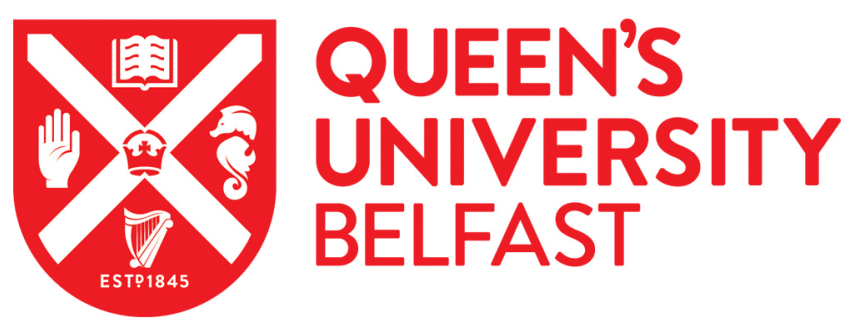

\title{
Do Individual Differences in Emotion Regulation Mediate the Relationship Between Mental Toughness and Symptoms of Depression?
}

Mutz, J., Clough, P. J., \& Papageorgiou, K. A. (2017). Do Individual Differences in Emotion Regulation Mediate the Relationship Between Mental Toughness and Symptoms of Depression? Journal of Individual Differences, 38, 71-82. https://doi.org/10.1027/1614-0001/a000224

\section{Published in:}

Journal of Individual Differences

\section{Document Version:}

Peer reviewed version

Queen's University Belfast - Research Portal:

Link to publication record in Queen's University Belfast Research Portal

\section{Publisher rights}

(c) 2017 Hogrefe Publications.

This article does not exactly replicate the final version published in the journal "Journal of Individual Differences. It is not a copy of the original published article and is not suitable for citation

\section{General rights}

Copyright for the publications made accessible via the Queen's University Belfast Research Portal is retained by the author(s) and / or other copyright owners and it is a condition of accessing these publications that users recognise and abide by the legal requirements associated with these rights.

Take down policy

The Research Portal is Queen's institutional repository that provides access to Queen's research output. Every effort has been made to ensure that content in the Research Portal does not infringe any person's rights, or applicable UK laws. If you discover content in the Research Portal that you believe breaches copyright or violates any law, please contact openaccess@qub.ac.uk. 
Do Individual Differences in Emotion Regulation Mediate the Relationship Between Mental Toughness and Symptoms of Depression?

\author{
Julian Mutz \\ King's College London \\ Peter Clough \\ Manchester Metropolitan University \\ Kostas A. Papageorgiou \\ Queen’s University Belfast
}

Author Note

Julian Mutz, Department of Psychological Medicine, Institute of Psychiatry, Psychology and Neuroscience, King's College London, United Kingdom; Peter Clough, Department of Psychology, Manchester Metropolitan University; Kostas A. Papageorgiou, School of Psychology, Queen’s University Belfast.

Correspondence concerning this article should be addressed to Julian Mutz;

Email: julian.mutz@gmail.com; Phone: +44(0)7519262936 


\begin{abstract}
Mental Toughness (MT) provides crucial psychological capacities for achievement in sports, education, and work settings. Previous research examined the role of MT in the domain of mental health and showed that MT is negatively associated with and predictive of fewer depressive symptoms in non-clinical populations. The present study aimed at 1) investigating to what extent mentally tough individuals use two emotion regulation strategies: cognitive reappraisal and expressive suppression; 2) exploring whether individual differences in emotion regulation strategy use mediate the relationship between MT and depressive symptoms. Three hundred sixty-four participants $(M=24.31$ years, $S D=9.16)$ provided self-reports of their levels of MT, depressive symptoms, and their habitual use of cognitive reappraisal and expressive suppression. The results showed a statistically significant correlation between MT and two commonly used measures of depressive symptoms. A small statistically significant positive correlation between MT and the habitual use of cognitive reappraisal was also observed. The correlation between MT and the habitual use of expressive suppression was statistically significant, but the size of the effect was small. A statistical mediation model indicated that individual differences in the habitual use of expressive suppression mediate the relationship between MT and depressive symptoms. No such effect was found for the habitual use of cognitive reappraisal. Implications of these findings and possible avenues for future research are discussed.
\end{abstract}

Keywords: mental toughness, depression, emotion regulation, cognitive reappraisal, expressive suppression 
Do Individual Differences in Emotion Regulation Mediate the Relationship Between Mental Toughness and Symptoms of Depression?

Previous research showed that individual differences in Mental Toughness (MT)

negatively correlate with depressive symptoms (e.g., Brand et al., 2014b). Furthermore, the habitual use of certain emotion regulation strategies is associated with individual variation in depressive symptoms (e.g., Haga, Kraft, \& Corby, 2009). The present study investigates whether individual differences in the habitual use of two emotion regulation strategies cognitive reappraisal and expressive suppression — mediate the relationship between MT and depressive symptoms.

Research on resilience has shown that several factors may have a protective function on individuals experiencing adversity (Luthar \& Zelazo, 2003). These range from having caring and supportive relationships (e.g., Crosnoe \& Elder, 2004) to personal characteristics such as hardiness (Kobasa, 1979). A construct that has recently been explored in relation to mental health outcomes — such as depressive symptoms — is MT.

\section{Mental Toughness}

MT refers to a broad array of positive characteristics, such as having a high sense of self-belief, which aid coping with difficult situations (Hardy, Imose, \& Day, 2014). A possible advantage of MT over other resilience traits is that it does not only reflect an effective coping mechanism for stressors; but it enables individuals to proactively seek out opportunities for personal growth (e.g., St Clair-Thompson et al., 2015). Another possible advantage of MT is that it can be developed partially through positive youth experiences (Gould, Griffes, \& Carson, 2011). These may include a particular motivational climate (e.g., enjoyment, challenge, and mastery experiences), external assets such as social support networks, and certain developmental experiences (e.g., critical incidents, competitive rivalry, vicarious experiences, and demonstration of ability; Connaughton, Hanton, \& Jones, 2010; 
26 Connaughton, Wadey, Hanton, \& Jones, 2008). For example, a study by (Jones \& Parker,

2013) showed that positive youth experiences were associated with higher levels of MT in young athletes. Specifically, initiative experiences were associated with high levels of MT and may therefore be worth promoting.

Mentally tough individuals approach, react to, and appraise pressure, challenge, and adversity as opportunities for self-development. Consequentially, they persist in reaching their goals (Gucciardi, Gordon, \& Dimmock, 2009a). Although MT was initially predominantly applied in the sport arena (Crust \& Keegan, 2010), it is now being researched in other performance environments such as the workplace (Godlewski \& Kline, 2012; Marchant et al., 2009) and education (McGeown, St Clair-Thompson, \& Clough, 2016; St Clair-Thompson et al., 2015). perceive themselves as being in control of life situations (i.e., feel and act as if they were influential), (2) show commitment to their actions (i.e., involve themselves rather than experience alienation from an encounter), (3) view challenge as an opportunity rather than a threat (i.e., holding the view that life is changeable and that this can lead to selfdevelopment), and (4) have high levels of confidence (i.e., a high sense of self-belief and faith in having the ability to achieve success).

Previous studies, which employed the 4C's model of MT, showed that individual variation in MT is associated with a number of positive outcomes. These include higher academic attainment and attendance, less counterproductive classroom behavior, greater social inclusion (St Clair-Thompson et al., 2015), better sleep quality (Brand et al., 2014a; Brand et al., 2014b), higher levels of psychological wellbeing (e.g., Stamp et al., 2015), more engagement with physical activity (Gerber et al., 2012), and better memory performance 
51 (Delaney, Goldman, King, \& Nelson-Gray, 2015; Dewhurst, Anderson, Cotter, Crust, \&

52 Clough, 2012). Clough and Strycharczyk (2015) coined the term 'the mental toughness

53 advantage' to describe this cluster of positive characteristics.

A review by McGeown et al. (2016) discussed MT in terms of the extent to which it aligns with other non-cognitive attributes, including resilience (e.g., Putwain, Nicholson, Connors, \& Woods, 2013), buoyancy (e.g., A. J. Martin \& Marsh, 2008), self-efficacy (e.g., Caprara, Vecchione, Alessandri, Gerbino, \& Barbaranelli, 2011; Stankov \& Lee, 2014), confidence (e.g., Stankov \& Lee, 2014), and motivation (e.g., Lepper, Corpus, \& Iyengar, 2005). They proposed that the main advantage of MT appears to be its multidimensionality, which offers the opportunity to consolidate a number of other concepts, such as resilience, and to investigate them beneath a single umbrella. Moreover, its use of multiple subcomponents may allow for the development of more targeted and flexible interventions compared to a unidimensional construct.

While the 4C's model of MT shares some conceptual foundation with hardiness, it differs in its additional emphasis on confidence in one's abilities and interpersonal relations. Hardiness was described by Kobasa (1979) as a personality disposition that provides resistance to stress. Mentally tough individuals are not only able to remain committed when confronting with stress, they are also confident about successfully completing their tasks and are assertive in social situations. MT is also distinct from grit, described by Duckworth, Peterson, Matthews, and Kelly (2007) as perseverance and passion for long-term goals. While individuals who score high on grit may work strenuously toward goals despite selfdoubt, individuals who score high on MT believe they are truly worthwhile people and maintain the self-confidence to achieve their goals. Another distinction is that MT not only places an emphasis on action, but also on affect, namely, emotional control. Mentally tough 
75 individuals are able to control their emotions effectively in the face of setbacks and 76 challenges.

\section{Mental Toughness and Emotion Regulation}

When individuals experience emotions, these typically promote behavioral response tendencies that are relevant to the emotion-eliciting event (Gross, 2015). Such response tendencies can either be helpful (e.g., when they enhance social interaction) or harmful (e.g., when they bias cognition and behavior in a maladaptive way; Gross \& Jazaieri, 2014). When emotions are unhelpful or even harmful, individuals typically draw on emotion regulation.

There are numerous emotion regulation strategies that exert variable influences on cognition, emotion, and behavior (Gross, 2001). Cognitive reappraisal involves reinterpreting the subjective meaning of emotion-eliciting stimuli to alter the emotional response, and it is regarded as an effective emotion regulation strategy in many contexts (Ochsner \& Gross, 2005). On the other hand, expressive suppression is characterized by ongoing efforts to inhibit emotion-expressive behavior and is frequently regarded as a less adaptive emotion regulation strategy (Moore, Zoellner, \& Mollenholt, 2008). However, it is worth noting that the consequences of different emotion regulation strategies may be context-dependent: for instance, cognitive reappraisal might be less adaptive when applied to stressors that can be controlled (Troy, Shallcross, \& Mauss, 2013).

There is currently no research that explored the type of emotion regulation strategies that mentally tough individuals use. It seems reasonable to suggest that MT would be closely linked to emotional regulation, and there are three main reasons to expect this: firstly, the 4C's model of MT has emotional control as one of its core dimensions. The validity of this inclusion has been supported by a number of authors (e.g., Crust \& Swann, 2011; Perry, Clough, Crust, Earle, \& Nicholls, 2013; St Clair-Thompson et al., 2015), although there has been some criticism of the validity of the model (e.g., Gucciardi, Hanton, and Mallett (2012) 
100 found no support for the psychometric properties of the Mental Toughness Questionnaire 48, 101 a self-report questionnaire widely used in MT research and based on the 4C's model). The

102 emotional control dimension of the 4C's model includes items with aspects of both cognitive 103 reappraisal and expressive suppression. Secondly, Nicholls et al. (2015) have shown that MT

104 is closely link to self-regulation in a wider context, allowing tougher individuals to prosper in 105 adverse circumstances. Finally, Nicholls, Polman, Levy, and Backhouse (2008) showed that 106 MT was associated with more problem-focused or approach coping strategies (i.e., reducing 107 or eliminating the stressor) such as mental imagery, effort expenditure, thought control, and 108 logical analysis. At the same time, mentally tough individuals used avoidance coping 109 strategies such as distancing, mental distraction or resignation less frequently. Kaiseler, 110 Polman, and Nicholls (2009) also reported that, in the context of a self-selected stressor, MT 111 was associated with more problem-focused coping strategies. Hence it could be argued that 112 mentally tough individuals more readily adapt problem-focused strategies because of their 113 ability to regulate their emotions.

114 Pertinently, Aldwin (2007) has suggested that the use of cognitive reappraisal may

115 facilitate problem-focused coping. For example, a student who feels distressed because she 116 received a poor grade on a very important exam might positively reappraise her situation as 117 an additional opportunity to revisit the course content before the re-sit. As a result, she may 118 feel less distressed about her current situation (due to cognitive reappraisal) and studies the 119 course content in greater depth, eventually passing the final exam (due to problem-solving).

120 At first glance, this might seem in contrast with Troy et al. (2013) who suggested that 121 cognitive reappraisal may be less adaptive when applied to controllable situations (e.g.,

122 individuals who decrease their negative emotions through cognitive reappraisal may lose

123 motivation to take action in situations in which action is needed, eventually leading to worse 124 outcomes). However, we suggest that cognitive reappraisal might in some instances still be 
125 adaptive when applied to a controllable stressor: if it is used to alter the emotional impact of a stressor and promotes problem-solving. Individuals who score high on MT may use cognitive reappraisal more often than other emotion regulation strategies (e.g., expressive 128 suppression) to enhance problem-focused coping strategies.

130 functioning, social interactions, and well-being (Gross \& John, 2003), whereas the habitual

131 use of expressive suppression is associated with decreased positive emotions, self-esteem,

132 and psychological adjustment (Nezlek \& Kuppens, 2008). In fact, previous studies

133 demonstrated that the habitual use of cognitive reappraisal is negatively associated with

134 depressive symptoms, whereas the habitual use of expressive suppression shows a positive 135 relationship with depressive symptoms (Haga et al., 2009).

\section{Mental Toughness and Depression}

A small number of studies have explored the degree to which MT is associated with individual differences in symptoms of psychopathology, for instance depression. It has been

139 shown that MT is predictive of fewer depressive symptoms 10 months later in a sample of 140 vocational students (Gerber, Brand, et al., 2013) and that MT is negatively associated with 141 depressive symptoms in high school students, undergraduates (Gerber, Kalak, et al., 2013), 142 and adolescents (Brand et al., 2014b). A possible explanation for the reported association

143 between MT and depressive symptoms is that individuals scoring high on MT are less

144 affected by emotion-provoking stimuli. However, MT and affect intensity/emotional 145 reactivity (i.e., the tendency to react strongly to emotion-eliciting events) were unrelated in a 146 sample of sport performers (Crust, 2009). As such, the idea that mentally tough individuals 147 remain unaffected by competition or adversity due to experience of less intense emotions was 148 not supported. Although this finding requires replication before one can make any firm 149 conclusions, a conceivable implication of this study is that emotion regulation plays an 
150 important role in understanding the relationship between MT and depressive symptoms.

151 Perhaps, mentally tough individuals cope with their emotions differently and resort on more

152 adaptive emotion regulation strategies, such as a more frequent use of cognitive reappraisal.

153 To date, no studies that have explored the role of emotion regulation strategies in explaining

154 the negative correlation between MT and depressive symptoms. This seems to be an

155 important area of investigation because understanding potential mediator variables could be useful in developing more targeted interventions to counteract depressive symptoms.

\section{The Present Study}

Most previous studies on MT and depressive symptoms involved participants in

159 highly stressful environments, potentially at high risk for maladjustment (Wynaden,

160 Wichmann, \& Murray, 2013). In order to test whether these findings can be generalized to a

161 broader range of people, the present study aims to extend previous research by investigating

162 how MT relates to depressive symptoms in a sample taken from the general population. This

163 is an important issue to address in order to determine whether or not MT is a useful concept

164 in the domain of mental health beyond groups of individuals in stressful environments. In

165 line with previous research, we hypothesized that: 1) MT is negatively correlated with

166 depressive symptoms; 2) individual differences in cognitive reappraisal are negatively

167 correlated with depressive symptoms; 3) individual differences in expressive suppression are

168 positively correlated with depressive symptoms. Since mentally tough individuals showed

169 fewer depressive symptoms in previous studies, we hypothesized that they differ in terms of

170 the strategies that they use to regulate their emotions. More specifically, we hypothesized

171 that: 4) MT is positively correlated with the habitual use of cognitive reappraisal; 5) MT is

172 negatively correlated with the habitual use of expressive suppression. Lastly, we tested a

173 statistical mediation model, which explores whether the relationship between MT and 
174 depressive symptoms is mediated by individual differences in the habitual use of cognitive reappraisal and expressive suppression.

176

177

178

179

180

181

182

183

184

185

186

187

188

189

190

191

192

193

194

195

196

197

\section{Method}

\section{Participants}

Participants $(N=364)$ were recruited online through advertisements on social networks (e.g., Facebook) as well as through word of mouth. Our sample comprised individuals of 43 different nationalities, with Singaporean and British participants constituting the two largest groups (24.5\% and $23.6 \%$, respectively). A majority of $50.3 \%$ of the participants were native English speakers. The mean age was 24.31 years $(S D=9.16$, range 18-79) and 56.9\% of the participants were female. Informed consent was obtained from all participants after they had received detailed information about the purpose of the study. London Metropolitan University's ethics committee granted approval for this project.

\section{Measures}

Mental toughness. The Mental Toughness Questionnaire 48 (MTQ48) is the most frequently used measure of MT as conceptualized by Clough et al. (2002). It has an average completion time of 10 minutes, and responses to its 48 items are given on a 5-point Likert scale anchored at $1=$ strongly disagree and $5=$ strongly agree. Twenty-two items are reverse coded; scores of the four main scales (challenge, commitment, confidence, and control) as well as four additional subscales (confidence in own abilities, interpersonal confidence, life control, and emotional control) can be obtained by calculating the mean of the scores that were reported for the items of each scale. An overall MT score can be obtained by calculating an overall mean score. Example items include "I can usually adapt myself to challenges that come my way" (challenge) and "I don’t usually give up under pressure" (commitment). The MTQ48 has generally shown good reliability, and the MTQ48 
has received support for its factor structure through confirmatory factor analyses and exploratory structural equation modelling (Horsburgh, Schermer, Veselka, \& Vernon, 2009).

Gross \& John, 2003) was used to assess individual differences in the habitual use of cognitive reappraisal and expressive suppression as emotion regulation strategies. The questionnaire has an average completion time of less than 2 minutes, and responses to its 10 items are given on a 7-point Likert scale ranging from $1=$ strongly disagree to $7=$ strongly agree. Scores of the two subscales of the ERQ can be calculated by summing up the scores that were reported for individual items of the scales. Higher scores indicate more frequent use of the respective emotion regulation strategy. Example items include "I control my emotions by changing the way I think about the situation I'm in" (cognitive reappraisal) and "I control my emotions by not expressing them" (expression suppression). Confirmatory factor analyses have supported the factor structure of the instrument (Melka, Lancaster, Bryant, \& Rodriguez, 2011).

212 (CUDOS; Zimmerman, Chelminski, McGlinchey, \& Posternak, 2008) was used to assess the 213 DSM-IV symptoms of major depressive disorder. It has an average completion time of less 214 than 3 minutes, and responses to its 16 items are given on a 5-point Likert scale indicating 215 how well the particular item describes the respondent during the past week $(0=$ not at all 216 true, $1=$ rarely true, $2=$ sometimes true, $3=$ often true, and $4=$ almost always true). An 217 overall score can be calculated by summing up the scores that were reported for individual 218 items of the questionnaire; higher scores indicate more depressive symptoms. Example items 219 include "I felt sad or depressed" and "I had more difficulties making decisions than usual". 220 The CUDOS was shown to demonstrate high internal consistency, test-retest reliability as 221 well as convergent and discriminant validity (Zimmerman et al., 2014). 

was used as an alternative instrument to measure the DSM-IV symptoms of major depressive disorder, since - to the best of our knowledge - no studies have assessed the construct and criterion validity of the CUDOS in the general population. It has an average completion time 226 of less than 2 minutes and assesses how often the respondent has experienced symptoms of 227 depression over the past two weeks. Responses to its nine items are given by assigning values of 0 to 3 points $(0=$ not at all, 1 = several days, 2 = more than half of the days, and 3 $=$ nearly every day). An overall score can be calculated by summing up the scores that were reported for individual items of the questionnaire; higher scores indicate more symptoms of

231 depression. Example items include "Feeling down, depressed, or hopeless" and "Feeling 232 tired or having little energy". The PHQ-9 not only recognizes clinical depression but also subthreshold levels of depressive symptoms in the general population (A. Martin, Rief,

234 Klaiberg, \& Braehler, 2006). High internal consistency, test-retest reliability as well as construct and criterion validity were demonstrated in a study by Bian, Li, Duan, and Wu

236 (2011).

\section{Procedure}

All questionnaires were combined to form a single document and made available online via SurveyMonkey (www.surveymonkey.com). Each participant received a message containing a link to the online questionnaire and password access as well as a unique

241 participant code. After they agreed to take part in our study, participants were asked for 242 demographic variables (age, gender, level of education, language, nationality and religion) 243 and contact details. Questionnaire completion was self-paced, and participants could only 244 proceed to the subsequent page once they had answered all items. Upon completion of the 245 study, participants were given an online written debrief.

\section{Statistical Analysis}


Demographics and questionnaire data were examined using SPSS (Version 20.0).

248 Since the scores of the PHQ-9 were positively skewed and peaked relative to the normal

249 distribution, we applied a square root transformation of the data before undertaking further

250 statistical analyses. Separate analyses with the untransformed PHQ-9 data yielded similar

251 results (not reported here). The scores of the remaining variables were approximately

252 normally distributed (see Table 1 for details). No observations were eliminated from the 253 analyses reported hereafter. The internal consistency of the questionnaires was estimated by

254 McDonald's (1999) Omega statistic using the MBESS package (Kelley \& Lai, 2012) for

255 RStudio (Version 0.98.932). Omega is a more sensible index of internal consistency than

256 Cronbach's alpha due to less risk for over-/underestimation of reliability (Dunn, Baguley, \&

257 Brunsden, 2014). Since previous research indicated that MT increases with age (Marchant et 258 al., 2009), we included age as a covariate in all analyses. Separate analyses without age as a 259 covariate were performed and yielded similar results (not reported here). We also tested 260 whether language, nationality, gender or religion had an effect on MT. However, none of 261 these variables significantly influenced MT and were thus not controlled for in further 262 analyses.

263 Mediation Analysis. To test the hypothesis that individual differences in the habitual 264 use of cognitive reappraisal and expressive suppression mediate the relationship between MT 265 and symptoms of depression, we performed hierarchical regression analyses using the 266 PROCESS macro for SPSS (Version 2.13; (Hayes, 2012). PROCESS utilizes an ordinary 267 least squares path analytical framework to estimate direct, indirect, and total effects of 268 mediation models. The direct effect provides an estimate of the effect of the independent 269 variable (IV) on the dependent variable (DV). The indirect effect of the IV on the DV via a 270 potential mediator (M) can be estimated from bias-corrected bootstrap 95\% confidence 271 intervals. Confidence intervals that do not contain zero give an indication of a significant 
272 mediation effect (Hayes, 2013). The total effect provides an estimate of the combined direct

273 and indirect effects. In the present study we used 5000 bootstrap resamples as suggested by

274 Preacher and Hayes (2008). The bootstrapping approach to estimating indirect effects is

275 advantageous over traditional procedures, as it does not rely on assumptions about the

276 distribution of the indirect effect.

Results

278

Descriptive statistics of the MTQ48, CUDOS, PHQ-9 as well as the cognitive reappraisal and expressive suppression scales of the ERQ are presented in Table 1.

280

281

[Insert Table 1]

282

283

Table 2 presents partial correlations between the main study variables and reliability

estimates. As expected, the MTQ48 total index was negatively associated with both

measures of depressive symptoms (CUDOS $r=-.53, p<.001,95 \%$ CI [-.60, -.44] and PHQ-

$9 r=-.49, p<.001,95 \%$ CI [-.56, -.40]). Cognitive reappraisal was negatively associated

with both the CUDOS and the PHQ-9 $(r=-.18, p<.001$, 95\% CI [-.29, -.06] and $r=-.19, p<$

$.001,95 \%$ CI [-.30, -.08], respectively), whereas expressive suppression showed a positive correlation with both measures of depressive symptoms (CUDOS $r=.18, p<.001$, 95\% CI $[.07, .29]$ and PHQ-9 $r=.19, p<.001,95 \%$ CI $[.08, .30])$. In line with our hypotheses, we also found a positive correlation between MT and the use of cognitive reappraisal $(r=.26, p$ $<.001,95 \%$ CI $[.15, .36])$ and a negative correlation between MT and the use of expressive suppression $(r=-.19, p<.001,95 \%$ CI [-.29, -.09]). 
Mediation Analysis

Figure 1 illustrates our proposed mediation model. Table 3 and Table 4 provide detailed statistics for our mediation analyses. In line with our hypotheses, the indirect effects of MT on depressive symptoms, through individual differences in expressive suppression, were statistically significant (PHQ-9: indirect effect $=-0.05, S E=0.03,95 \%$ CI $[-0.131$, 0.007]; CUDOS: indirect effect $=-0.44, S E=0.27,95 \%$ CI $[-1.108,-0.020])$. However, we failed to obtain evidence that individual differences in cognitive reappraisal mediate the relationship between MT and depressive symptoms (PHQ-9: indirect effect $=-0.05, S E$ $=0.04,95 \%$ CI $[-0.137,0.019]$; CUDOS: indirect effect $=-0.29, S E=0.37,95 \%$ CI $[-1.123$, 0.355]). To test whether an alternative mediation model with emotion regulation strategy use as the IV, MT as the mediator, and depressive symptoms as the DV might be more appropriate in accounting for the relationship between MT, depressive symptoms, and emotion regulation strategy use, we ran post-hoc exploratory analyses. The total effect sizes for such alternative model were all smaller than .04, hence this seems less supported by the data compared with our initial proposal (data not reported here).

[Insert Figure 1]

[Insert Table 3]

317 [Insert Table 4]

\section{Discussion}


322 that the habitual use of cognitive reappraisal was negatively associated with depressive

323 symptoms, whereas the opposite applied to the habitual use of expressive suppression (Haga

324 et al., 2009). We examined the relationship between these variables in our sample and

325 investigated how individual variation in MT relates to the habitual use of cognitive

326 reappraisal and expressive suppression. Lastly, we tested a statistical mediation model that

327 explored whether individual differences in the habitual use of cognitive reappraisal and 328 expressive suppression mediate the relationship between MT and depressive symptoms.

329 In line with previous studies (Brand et al., 2014b; Gerber, Brand, et al., 2013; Gerber,

330 Kalak, et al., 2013), we showed that there is a significant and moderately strong inverse

331 relationship between MT and two measures of depressive symptoms. We extend prior

332 research by demonstrating that this finding does not only apply to selective populations, such

333 as adolescents or university students, but also to a more inclusive sample taken from the

334 general population. As such, MT seems to be a useful concept in the domain of mental

335 health, beyond groups of individuals in potentially highly stressful environments. Studying

336 MT in relation to individual differences in depressive symptoms is important, given that there

337 is a close relationship between psychological resources and psychopathological symptoms

338 (Lee \& Hankin, 2009). Furthermore, MT has been linked to educational achievement (St

339 Clair-Thompson et al., 2015), and psychopathological symptoms have been shown to

340 associate with decreased performance in educational (Andrews \& Wilding, 2004) and

341 occupational (Wang et al., 2014) settings. Hence, exploring whether MT is linked to

342 depressive symptoms can have significant implications for understanding educational and

343 work performance. Finally, given that MT is at least to some extent amenable to

344 development through targeted interventions (Crust \& Clough, 2011; Gucciardi, Gordon, \&

345 Dimmock, 2009b; Sheard \& Golby, 2006) MT training might appeal to those individuals who

346 are skeptical about the meaning and usefulness of more conventional health interventions 
347 (Gerber, Kalak, et al., 2013). As such, MT constitutes an important concept in the domain of 348 mental health, and fostering MT might be a valuable intervention to counteract depressive 349 symptoms.

We also showed that the habitual use of cognitive reappraisal is negatively associated with depressive symptoms, while the habitual use of expressive suppression showed the

352 reverse pattern. This finding is in line with much of the emotion regulation literature (Gross, 353 Richards, \& John, 2006; John \& Gross, 2004) and provides some additional support for the common view that cognitive reappraisal is — in most contexts - a more adaptive emotion regulation strategy than expressive suppression (Haga et al., 2009). It needs to be noted that although these associations are statistically highly significant, the effect sizes are relatively small. This is perhaps not surprising, given the plethora of factors precipitating and perpetuating depressive symptoms. The size of this effect is similar to that obtained through a meta-analysis by Aldao, Nolen-Hoeksema, and Schweizer (2010), which looked at the association between cognitive reappraisal and depressive symptoms based on the data of seven studies.

The present study adds to the current literature on MT in that it is the first study that investigated how mentally tough individuals regulate their emotions, despite the centrality of emotional control in most models of MT. We showed that individuals scoring high on MT more frequently use cognitive reappraisal to regulate their emotions, although the size of this

366 effect is comparatively small. They resort to the use of expressive suppression less

367 frequently; but given the marginal size of this effect, this finding is less conclusive. We 368 could only partially support our hypothesis that the relationship between MT and symptoms 369 of depression is mediated by individual differences in emotion regulation strategy use. The analyses showed that individual differences in the habitual use of expressive suppression appear to mediate the relationship between MT and depressive symptoms. However, we did 
372 not obtain supporting evidence for our hypothesis that individual differences in the habitual

373 use of cognitive reappraisal mediate the relationship between MT and symptoms of

374 depression. Since cognitive reappraisal tends to be less adaptive when applied to controllable

375 situations (Troy et al., 2013), which individuals scoring high on MT, conceptually, perceive

376 more often, the boundary conditions of reappraisal effectiveness might explain the lack of a

377 significant mediation effect. However, whether individuals scoring high on MT actually

378 experience controllable situations more often has not been directly tested and would open up

379 possible avenues for future research.

There are several alternative explanations for the association between MT and

381 depressive symptoms. It might be that the dysfunctional thoughts and maladaptive

382 tendencies that are characteristic of depressive symptoms are incompatible with current conceptualizations of MT. Whereas mentally tough individuals have a strong tendency to

384 view their personal environment as controllable, perceive themselves as capable and influential, and stay committed under adverse circumstances, individuals experiencing

386 depressive symptoms typically manifest the reverse pattern. Another finding that could 387 partially explain why mentally tough individuals show fewer depressive symptoms is that 388 individuals with high levels of MT more frequently rely on problem-oriented coping (i.e., 389 strategies used to minimize distress by reducing or eliminating the stressor) rather than 390 emotion-focused (i.e., regulate emotional arousal and distress) or avoidance coping (i.e., 391 behavioral or psychological efforts to disengage from a stressful situation; (Nicholls, Polman, 392 Levy, \& Backhouse, 2009). Individuals suffering from depression frequently use avoidance coping strategies (Cribb, Moulds, \& Carter, 2006), which tend to be less effective in reducing

394 the negative consequences associated with experiencing adversity. Accordingly, individuals 395 with low levels of MT may not effectively cope with stress factors, possibly causing an 396 increase in depressive symptoms. 


\section{Limitations}

A number of limitations in the present study need to be acknowledged. Even though online data collection has some advantages, such as spending less economic resources or reaching large and diverse samples (Gosling \& Mason, 2015), there is less control over the actual completion of the questions (e.g., alone or in the company of others), which might affect responses. As we exclusively relied on self-reported data, we cannot rule out the possibility that the responses were influenced by social desirability and common-method variance (Podsakoff, MacKenzie, Lee, \& Podsakoff, 2003). Furthermore, the cross sectional design of our study did not allow for determining a causal explanation of our data. It remains unclear whether the habitual use of expressive suppression is unfavorable regarding depressive symptoms or depressive symptoms lead to a suppression of emotions. Future research should address these issues by employing longitudinal designs or randomized controlled trials to obtain causal evidence and to test whether or not we can alleviate depressive symptoms by strengthening the MT of an individual or by reducing the habitual use of expressive suppression. Indeed, it would be worthwhile to investigate in future studies whether bolstering levels of MT or reinforcing the use of more adaptive emotion regulation strategies is a more effective strategy to counteract depressive symptoms. Furthermore, exploring physiological parameters might shed light on the relationship between MT and depressive symptoms. A number of studies evinced that there is an association between physical activity and mental health (Deslandes et al., 2009; Fuchs, Hahn, \& Schwarzer, 1994). Ekkekakis and Acevedo (2006), for instance, showed that participants reported improved mood after exercising, and Azar, Ball, Salmon, and Cleland (2008) have shown an inverse relationship between physical activity and depression. Since mentally tough individuals show higher engagement with physical activity (Gerber et al., 2012), this relationship might constitute another pathway through which MT exerts its effects on 
422 depressive symptoms. It has also been shown that MT relates to better sleep quality,

423 including fewer awakenings after sleep onset, less light sleep and more deep sleep (Brand et

424 al., 2014a; Brand et al., 2014b). Since sleep disturbance is a common characteristic of

425 depression and is predictive of recurrent depression (Roberts, Shema, Kaplan, \& Strawbridge,

426 2014). As such, future research could explore whether mentally tough individuals show less

427 depressive symptoms due to better sleep quality.

428 In accordance with much recent research, we looked at the two emotion regulation

429 strategies that fulfill the two most frequently reported objectives of emotion regulation:

430 altering emotional experience and expression (Gross et al., 2006). However, it is not clear to

431 what extent a global self-report measure of emotion regulation captures what emotion

432 regulation strategies are used in everyday life; it also does not provide information on the

433 effects of these strategies. Since the effectiveness of emotion regulation is to some extent

434 context-dependent, future investigations should incorporate assessment of contextual factors

435 in which emotion regulation is imbedded (e.g., whether or not the stressor is controllable). It

436 may also be important to assess the effectiveness of emotion regulation strategy

437 implementation in future studies: perhaps mentally tough individuals use the same emotion

438 regulation strategies as others but implement them more effectively. Difficulties in emotion

439 regulation may arise from a number of sources: 1) the identification of the need to regulate

440 emotions; 2) the selection among available regulatory options; 3) implementation of a

441 selected regulatory tactic; 4) monitoring of the implemented emotion regulation strategy over

442 time (for an extensive review see Sheppes, Suri, and Gross (2015)). The present study only

443 assessed emotion regulation strategy implementation. Moreover, because there are numerous

444 other emotion regulation strategies available, future research might provide more insights on

445 how mentally tough individuals regulate their emotions by examining different strategies, and 
446 examine how effectively mentally tough individuals alter the intensity, duration, frequency, 447 and category of emotional responses; and how flexible they are in using different strategies.

448 Conflict of interest

449 The entire study was conducted without external funding. All authors declare no

450 conflicts of interest.

451

452

453

454

455

456

457

458

459

460

461

462

463

464

465

466

467

468

469

470 
471

472

473

474

475

476

477

478

479

480

481

482

483

484

485

486

487

488

489

490

491

492

493

494

495

\section{References}

Aldao, A., Nolen-Hoeksema, S., \& Schweizer, S. (2010). Emotion-regulation strategies across psychopathology: A meta-analytic review. Clinical Psychology Review, 30(2), 217-237.

Aldwin, C. M. (2007). Stress, coping, and development: An integrative perspective: New York, NY: Guilford Press.

Andrews, B., \& Wilding, J. M. (2004). The relation of depression and anxiety to life - stress and achievement in students. British Journal of Psychology, 95(4), 509-521.

Azar, D., Ball, K., Salmon, J., \& Cleland, V. (2008). The association between physical activity and depressive symptoms in young women: A review. Mental Health and Physical Activity, 1(2), 82-88.

Bian, C., Li, C., Duan, Q., \& Wu, H. (2011). Reliability and validity of patient health questionnaire: depressive syndrome module for outpatients. Scientific Research and Essays, 6(2), 278-282.

Brand, S., Gerber, M., Kalak, N., Kirov, R., Lemola, S., Clough, P., . . Holsboer-Trachsler, E. (2014a). Adolescents with greater mental toughness show higher sleep efficiency, more deep sleep and fewer awakenings after sleep onset. Journal of Adolescent Health, 54(1), 109-113.

Brand, S., Gerber, M., Kalak, N., Kirov, R., Lemola, S., Clough, P., . . . Holsboer-Trachsler, E. (2014b). “Sleep well, our tough heroes!”-In adolescence, greater mental toughness is related to better sleep schedules. Behavioral Sleep Medicine, 12(6), 444454.

Caprara, G. V., Vecchione, M., Alessandri, G., Gerbino, M., \& Barbaranelli, C. (2011). The contribution of personality traits and self - efficacy beliefs to academic achievement: A longitudinal study. British Journal of Educational Psychology, 81(1), 78-96. 
496 Clough, P., Earle, K., \& Sewell, D. (2002). Mental toughness: The concept and its measurement. In I. M. Cockerill (Ed.), Solutions in sport psychology (pp. 32-43). Boston, MA: Cengage Learning.

Clough, P., \& Strycharczyk, D. (2015). Developing mental toughness: Coaching strategies to improve performance, resilience and wellbeing. London, UK: Kogan Page Publishers.

Connaughton, D., Hanton, S., \& Jones, G. (2010). The development and maintenance of mental toughness in the world's best performers. The Sport Psychologist, 24(2), 168193.

504 Connaughton, D., Wadey, R., Hanton, S., \& Jones, G. (2008). The development and maintenance of mental toughness: Perceptions of elite performers. Journal of Sports Sciences, 26(1), 83-95.

Cribb, G., Moulds, M. L., \& Carter, S. (2006). Rumination and experiential avoidance in depression. Behaviour Change, 23(03), 165-176.

509 Crosnoe, R., \& Elder, G. H. (2004). Family dynamics, supportive relationships, and educational resilience during adolescence. Journal of Family Issues, 25(5), 571-602.

511 Crust, L. (2009). The relationship between mental toughness and affect intensity. Personality $512 \quad$ and Individual Differences, 47(8), 959-963.

513 Crust, L., \& Clough, P. J. (2011). Developing mental toughness: From research to practice. $514 \quad$ Journal of Sport Psychology in Action, 2(1), 21-32.

515 Crust, L., \& Keegan, R. (2010). Mental toughness and attitudes to risk-taking. Personality $516 \quad$ and Individual Differences, 49(3), 164-168.

517 Crust, L., \& Swann, C. (2011). Comparing two measures of mental toughness. Personality and Individual Differences, 50(2), 217-221. 
519 Delaney, P. F., Goldman, J. A., King, J. S., \& Nelson-Gray, R. O. (2015). Mental toughness, reinforcement sensitivity theory, and the five-factor model: Personality and directed forgetting. Personality and Individual Differences, 83, 180-184.

522 Deslandes, A., Moraes, H., Ferreira, C., Veiga, H., Silveira, H., Mouta, R., . . Laks, J. (2009). Exercise and mental health: Many reasons to move. Neuropsychobiology, 59(4), 191-198.

Dewhurst, S. A., Anderson, R. J., Cotter, G., Crust, L., \& Clough, P. (2012). Identifying the cognitive basis of mental toughness: Evidence from the directed forgetting paradigm. Personality and Individual Differences, 53(5), 587-590.

Duckworth, A. L., Peterson, C., Matthews, M. D., \& Kelly, D. R. (2007). Grit: perseverance and passion for long-term goals. Journal of Personality and Social psychology, 92(6), 1087-1101.

Ekkekakis, P., \& Acevedo, E. O. (2006). Affective responses to acute exercise: Toward a psychobiological dose-response model. In E. O. Acevedo \& P. Ekkekakis (Eds.), Psychobiology of physical activity (pp. 91-109). Champaign, IL: Human Kinetics.

534 Fuchs, R., Hahn, A., \& Schwarzer, R. (1994). Effekte sportlicher aktivität auf selbstwirksamkeits-erwartung und gesundheit in einer streßreichen lebenssituation. Sportwissenschaft, 24(1), 67-81.

537 Gerber, M., Brand, S., Feldmeth, A. K., Lang, C., Elliot, C., Holsboer-Trachsler, E., \& Pühse, U. (2013). Adolescents with high mental toughness adapt better to perceived stress: A longitudinal study with Swiss vocational students. Personality and Individual Differences, 54(7), 808-814.

541 Gerber, M., Kalak, N., Lemola, S., Clough, P., Perry, J. L., Pühse, U., . . Brand, S. (2013). Are adolescents with high mental toughness levels more resilient against stress? Stress and Health, 29(2), 164-171. 
544 Gerber, M., Kalak, N., Lemola, S., Clough, P., Pühse, U., Elliot, C., . . . Brand, S. (2012).

545

546

Adolescents' exercise and physical activity are associated with mental toughness. Mental Health and Physical Activity, 5(1), 35-42.

Godlewski, R., \& Kline, T. (2012). A model of voluntary turnover in male Canadian Forces recruits. Military Psychology, 24(3), 251-269.

Gosling, S. D., \& Mason, W. (2015). Internet research in psychology. Annual Review of Psychology, 66, 877-902.

Gould, D., Griffes, K., \& Carson, S. (2011). Mental toughness as a life skill. In D. Gucciardi \& S. Gordon (Eds.), Mental toughness in sport: Developments in theory and research (pp. 163-186). Abingdon-on-Thames, UK: Routledge.

Gross, J. J. (2001). Emotion regulation in adulthood: Timing is everything. Current Directions in Psychological Science, 10(6), 214-219.

Gross, J. J. (2015). Emotion regulation: Current status and future prospects. Psychological Inquiry, 26(1), 1-26.

Gross, J. J., \& Jazaieri, H. (2014). Emotion, emotion regulation, and psychopathology: An affective science perspective. Clinical Psychological Science, 2(4), 387-401.

Gross, J. J., \& John, O. P. (2003). Individual differences in two emotion regulation processes: Implications for affect, relationships, and well-being. Journal of Personality and Social Psychology, 85(2), 348-362.

Gross, J. J., Richards, J. M., \& John, O. P. (2006). Emotion regulation in everyday life. In D. K. Snyder, J. Simpson, \& J. N. Hughes (Eds.), Emotion regulation in couples and families: Pathways to dysfunction and health (pp. 13-35). Washington, DC: American Psychological Association. 
567 Gucciardi, D. F., Gordon, S., \& Dimmock, J. A. (2009a). Advancing mental toughness

568

569

570

571

572

573

574

575

576

577

578

579

580

581

582

583

584

585

586

587

588

589

590 research and theory using personal construct psychology. International Review of Sport and Exercise Psychology, 2(1), 54-72.

Gucciardi, D. F., Gordon, S., \& Dimmock, J. A. (2009b). Evaluation of a mental toughness training program for youth-aged Australian footballers: I. A quantitative analysis. Journal of Applied Sport Psychology, 21(3), 307-323.

Gucciardi, D. F., Hanton, S., \& Mallett, C. J. (2012). Progressing measurement in mental toughness: A case example of the Mental Toughness Questionnaire 48. Sport, Exercise, and Performance Psychology, 1(3), 194-214.

Haga, S. M., Kraft, P., \& Corby, E.-K. (2009). Emotion regulation: Antecedents and wellbeing outcomes of cognitive reappraisal and expressive suppression in cross-cultural samples. Journal of Happiness Studies, 10(3), 271-291.

Hardy, J. H., Imose, R. A., \& Day, E. A. (2014). Relating trait and domain mental toughness to complex task learning. Personality and Individual Differences, 68, 59-64.

Hayes, A. F. (2012). PROCESS [Macro]. Retrieved from http://afhayes.com/introduction-tomediation-moderation-and-conditional-process-analysis.html

Hayes, A. F. (2013). Introduction to mediation, moderation, and conditional process analysis: A regression-based approach. New York, NY: Guilford Press.

Horsburgh, V. A., Schermer, J. A., Veselka, L., \& Vernon, P. A. (2009). A behavioural genetic study of mental toughness and personality. Personality and Individual Differences, 46(2), 100-105.

John, O. P., \& Gross, J. J. (2004). Healthy and unhealthy emotion regulation: Personality processes, individual differences, and life span development. Journal of Personality, 72(6), 1301-1334. 
591 Jones, M. I., \& Parker, J. K. (2013). What is the size of the relationship between global mental toughness and youth experiences? Personality and Individual Differences, 54(4), 519-523.

594 Kaiseler, M., Polman, R., \& Nicholls, A. (2009). Mental toughness, stress, stress appraisal, 595 coping and coping effectiveness in sport. Personality and Individual Differences, 47(7), 728-733.

Kobasa, S. C. (1979). Stressful life events, personality, and health: an inquiry into hardiness. 598 Journal of Personality and Social Psychology, 37(1), 1-11.

599 Kroenke, K., Spitzer, R. L., \& Williams, J. B. W. (2001). The PHQ - 9. Journal of General 600 Internal Medicine, 16(9), 606-613.

601

Lee, A., \& Hankin, B. L. (2009). Insecure attachment, dysfunctional attitudes, and low selfesteem predicting prospective symptoms of depression and anxiety during adolescence. Journal of Clinical Child \& Adolescent Psychology, 38(2), 219-231.

Lepper, M. R., Corpus, J. H., \& Iyengar, S. S. (2005). Intrinsic and extrinsic motivational 605 orientations in the classroom: age differences and academic correlates. Journal of 606 Educational Psychology, 97(2), 184-196.

Luthar, S. S., \& Zelazo, L. B. (2003). Research on resilience: An integrative review. In S. S.

Martin, A., Rief, W., Klaiberg, A., \& Braehler, E. (2006). Validity of the brief patient health questionnaire mood scale (PHQ-9) in the general population. General Hospital Psychiatry, 28(1), 71-77. 
616 Martin, A. J., \& Marsh, H. W. (2008). Workplace and academic buoyancy: Psychometric assessment and construct validity amongst school personnel and students. Journal of Psychoeducational Assessment, 26(2), 168-184.

McGeown, S. P., St Clair-Thompson, H., \& Clough, P. (2016). The study of non-cognitive attributes in education: proposing the mental toughness framework. Educational Review, 68(1), 96-113.

Melka, S. E., Lancaster, S. L., Bryant, A. R., \& Rodriguez, B. F. (2011). Confirmatory factor and measurement invariance analyses of the Emotion Regulation Questionnaire. Journal of Clinical Psychology, 67(12), 1283-1293.

Moore, S. A., Zoellner, L. A., \& Mollenholt, N. (2008). Are expressive suppression and cognitive reappraisal associated with stress-related symptoms? Behaviour Research and Therapy, 46(9), 993-1000.

Nezlek, J. B., \& Kuppens, P. (2008). Regulating positive and negative emotions in daily life. Journal of Personality, 76(3), 561-580.

630 Nicholls, A. R., Perry, J., Jones, L., Sanctuary, C., Carson, F., \& Clough, P. (2015). The mediating role of mental toughness in sport. The Journal of Sports Medicine and Physical Fitness, 55(7-8), 824.

Nicholls, A. R., Polman, R. C., Levy, A. R., \& Backhouse, S. H. (2008). Mental toughness, optimism, pessimism, and coping among athletes. Personality and Individual Differences, 44(5), 1182-1192.

Nicholls, A. R., Polman, R. C. J., Levy, A. R., \& Backhouse, S. H. (2009). Mental toughness in sport: Achievement level, gender, age, experience, and sport type differences. Personality and Individual Differences, 47(1), 73-75.

639 Ochsner, K. N., \& Gross, J. J. (2005). The cognitive control of emotion. Trends in Cognitive Sciences, 9(5), 242-249. 
641 Perry, J. L., Clough, P., Crust, L., Earle, K., \& Nicholls, A. R. (2013). Factorial validity of the Mental Toughness Questionnaire-48. Personality and Individual Differences, 54(5), 587-592.

Podsakoff, P. M., MacKenzie, S. B., Lee, J.-Y., \& Podsakoff, N. P. (2003). Common method biases in behavioral research: a critical review of the literature and recommended remedies. Journal of Applied Psychology, 88(5), 879-903.

Preacher, K. J., \& Hayes, A. F. (2008). Asymptotic and resampling strategies for assessing and comparing indirect effects in multiple mediator models. Behavior Research Methods, 40(3), 879-891.

Putwain, D. W., Nicholson, L. J., Connors, L., \& Woods, K. (2013). Resilient children are less test anxious and perform better in tests at the end of primary schooling. Learning and Individual Differences, 28, 41-46.

Roberts, R. E., Shema, S. J., Kaplan, G. A., \& Strawbridge, W. J. (2014). Sleep complaints and depression in an aging cohort: A prospective perspective. American Journal of Psychiatry, 157(1), 81-88.

Sheard, M., \& Golby, J. (2006). Effect of a psychological skills training program on swimming performance and positive psychological development. International Journal of Sport and Exercise Psychology, 4(2), 149-169.

Sheppes, G., Suri, G., \& Gross, J. J. (2015). Emotion regulation and psychopathology. Annual Review of Clinical Psychology, 11, 379-405. (2015). Mental toughness in education: Exploring relationships with attainment, attendance, behaviour and peer relationships. Educational Psychology 35(7), 886-907. 
664 Stamp, E., Crust, L., Swann, C., Perry, J., Clough, P., \& Marchant, D. (2015). Relationships

665

666

667

668

669

670

671

672

673

674

675

676

677

678

679

680

681

682

683 between mental toughness and psychological wellbeing in undergraduate students. Personality and Individual Differences, 75, 170-174.

Stankov, L., \& Lee, J. (2014). Quest for the best non-cognitive predictor of academic achievement. Educational Psychology, 34(1), 1-8.

Troy, A. S., Shallcross, A. J., \& Mauss, I. B. (2013). A person-by-situation approach to emotion regulation cognitive reappraisal can either help or hurt, depending on the context. Psychological Science, 24(12), 2505-2514.

Wang, P. S., Beck, A. L., Berglund, P., McKenas, D. K., Pronk, N. P., Simon, G. E., \& Kessler, R. C. (2014). Effects of major depression on moment-in-time work performance. American Journal of Psychiatry, 161(10), 1885-1891.

Wynaden, D., Wichmann, H., \& Murray, S. (2013). A synopsis of the mental health concerns of university students: Results of a text-based online survey from one Australian university. Higher Education Research \& Development, 32(5), 846-860.

Zimmerman, M., Chelminski, I., McGlinchey, J. B., \& Posternak, M. A. (2008). A clinically useful depression outcome scale. Comprehensive Psychiatry, 49(2), 131-140.

Zimmerman, M., Chelminski, I., Young, D., Dalrymple, K., Walsh, E., \& Rosenstein, L. (2014). A clinically useful self-report measure of the DSM-5 anxious distress specifier for major depressive disorder. The Journal of Clinical Psychiatry, 75(6), 601-607. 